\title{
Quantifying late gadolinium enhancement on CMR provides additional prognostic information in early risk-stratification of nonischemic cardiomyopathy: a cohort study
}

\author{
Pauli Pöyhönen ${ }^{1 *}$, Sari Kivistö ${ }^{2}$, Miia Holmström² ${ }^{2}$ and Helena Hänninen ${ }^{1}$
}

\begin{abstract}
Background: Suspected nonischemic cardiomyopathy (NICM) is a common clinical setting with highly variable prognosis. Early noninvasive risk-stratification is important for justification of invasive examinations, specific treatment and patient surveillance. We studied the additional prognostic value of late gadolinium enhancement (LGE) and segmental wall motion abnormality (SWMA) extent on cardiovascular magnetic resonance (CMR) compared to traditional risk factors in suspected NICM.
\end{abstract}

Methods: In this observational cohort study, we enrolled 86 consecutive patients referred for CMR due to suspected NICM. Patients with ischemic cardiomyopathy were excluded. CMR images were analysed for left ventricular LGE and SWMA extents and patients were followed-up for major adverse cardiac events (MACE), including cardiovascular death, aborted sudden death and cardiac transplantation.

Results: Of 86 patients (median age: 53 years, 45\% female), mainly presenting with ventricular arrhythmias (40\%) and congestive heart failure (44\%), 76\% were finally diagnosed with NICM, 17\% with left ventricle hypertrophy and $7 \%$ with idiopathic arrhythmia. On CMR, 61 patients (71\%) had LGE and 56 (65\%) SWMA. During median follow-up of 835 days, 15 patients (17\%) reached MACE. In univariant analysis, LGE volume (hazard ratio [HR] 1.028 per 1\% increase in LGE, $p<0.001$ ), left ventricular ejection fraction (LVEF) (HR 0.959, $p=0.009$ ) and SWMA score (HR 1.067, $p=0.012$ ) had strongest associations with MACE. In multivariate analysis, the best overall model for event prediction included LGE volume (HR 1.027, $p=0.003$ ), sustained ventricular tachycardia (HR 4.7, $p=0.011)$ and LVEF (HR 0.962, $p=0.034$ ). Among patients with LGE, there was an event rate of $26 \%$ (14 of 61) versus $4 \%$ ( 1 of 25 ) in patients without LGE $(p=0.041$, Log-rank). The highest event rate was observed in patients with LGE volume of $\geq 17 \%$. Patients without SWMA did not experience MACE ( $p=0.002$, Log-rank), giving additional information in the subgroup of patients with preserved LVEF ( $\geq 50 \%)$.

Conclusions: In suspected NICM, presenting with ventricular arrhythmias or heart failure, LGE extent gives additional prognostic information compared to traditional risk factors, while the absence of SWMA may give prognostic information beyond normal LVEF. Even though the final diagnosis is uncertain in NICM, extensive amount of LGE should be considered as a sign of poor prognosis.

Keywords: Cardiomyopathy, Nonischemic cardiomyopathy, Cardiovascular magnetic resonance imaging, Late gadolinium enhancement, Segmental wall motion abnormality, Prognosis, Risk-stratification

\footnotetext{
* Correspondence: pauli.poyhonen@helsinkifi

${ }^{1}$ Heart and Lung Center, Division of Cardiology, Helsinki University Central

Hospital, Po BOX 340, 00029 HUCH Helsinki, Finland

Full list of author information is available at the end of the article
}

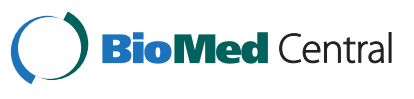

(c) 2014 Pöyhönen et al.; licensee BioMed Central Ltd. This is an Open Access article distributed under the terms of the Creative Commons Attribution License (http://creativecommons.org/licenses/by/4.0), which permits unrestricted use, distribution, and reproduction in any medium, provided the original work is properly credited. The Creative Commons Public Domain Dedication waiver (http://creativecommons.org/publicdomain/zero/1.0/) applies to the data made available in this article, unless otherwise stated. 


\section{Background}

Nonischemic cardiomyopathy (NICM) is a common diagnostic challenge in clinical cardiology. NICMs are a diverse group of myocardial diseases associated with mechanical or electrical dysfunction and usually inappropriate ventricular hypertrophy or dilatation, not related to atherosclerosis [1]. The etiology of NICM may be genetic, acquired or secondary to systemic disease, with highly variable clinical presentation and prognosis $[2,3]$. However, the specific diagnosis of NICM is initially often unexplained and reaching the final diagnosis may be a timely process. Thus, early risk-stratification of NICM is valuable for justification of potentially harmful invasive examinations [4] and proper patient surveillance. Although left ventricular ejection fraction (LVEF), ventricular tachycardia (VT) and NYHA functional classification are all well known predictors of cardiac mortality [5], there is increasing evidence that noninvasive cardiovascular magnetic resonance (CMR) imaging with late gadolinium enhancement (LGE) provides additional information in the risk-stratification of NICM [6-9].

The prognostic value of LGE has been shown in several specific cardiac diseases, including ischemic and nonischemic cardiomyopathies [10-15]. LGE, i.e. delayed enhancement on CMR images after intravenous injection of gadolinium-contrast, visualizes increases in the regional extracellular space related to myocardial necrosis, fibrosis, oedema or infiltration. Ideally, the prognostic value of LGE should be interpreted in the context of the specific disease, since the etiology of NICM itself carries a prognostic value [3]. However, since the specific diagnosis of NICM often remains unclear even after CMR, the prognostic value of LGE must frequently be considered in suspected or newly diagnosed NICM. There is limited information on the prognostic value of LGE in nonselected consecutive patients with newly diagnosed NICM, which reflects the usual real-life clinical scenario [8]. Furthermore, most studies have evaluated the prognostic value of the presence of LGE [9], and there are only few studies on quantifying the extent of LGE in NICM, considering the best prognostic ability $[10,16,17]$.

In this study, the visual scoring method based on the standard 17-segment model was used to estimate the global extent of LGE in the left ventricle (LV) [18]. This method has been shown to be rapid and accurate method to estimate LGE both in ischemic and nonischemic cardiomyopathies $[7,19,20]$.

Segmental wall motion abnormalities (SWMA), visualized by echocardiography, have been used for long to detect myocardial ischemia and viability in ischemic cardiomyopathy [21]. However, CMR with standard cineimaging has been shown to be the most accurate and reproducible method to study left ventricular regional function $[22,23]$. Recently, visual scoring of SWMA has been shown to be accurate and reproducible method to estimate LVEF, known strong predictor of cardiac mortality [24]. Nevertheless, it is unclear if SWMA gives additional prognostic information beyond LVEF in NICM.

In this cohort study, we evaluated the additional prognostic value of LGE and SWMA extent on CMR compared to traditional cardiac risk factors in a common clinical setting of suspected NICM. We hypothesized that even though the eventual diagnosis is uncertain in suspected NICM, LGE or SWMA extent might provide valuable information in early risk-stratification.

\section{Methods}

\section{Study design and patient selection}

This observational cohort study was performed in the Heart and Lung Center at the Helsinki University Central Hospital $(\mathrm{HUCH})$. Altogether 98 consecutive patients referred for LGE CMR due to suspected NICM between November 2008 and April 2010 (18 months) were enrolled to the study. All enrolled patients had suspected NICM, i.e. symptoms of heart failure, mechanical and/or electrical cardiac dysfunction, usually associated with inappropriate ventricular dilatation or hypertrophy, or cardiac enzyme elevation, not related to atherosclerosis [1]. Before CMR, no patient had history of myocardial infarction or documented significant coronary artery disease (CAD) defined as $>50 \%$ stenosis in two or more epicardial vessels or $>50 \%$ stenosis in left main or proximal left anterior descending artery [25]. Also, no patient had known valvular or congenital heart disease. After CMR, six patients were lost due to lack of complete baseline data and another six patients were excluded due to ischemic cardiomyopathy. Thus, eventually 86 patients were eligible for analysis. The study protocol was approved by the institutional review board of $\mathrm{HUCH}$. All data in this study were analysed retrospectively.

\section{Data acquisition}

Medical records were reviewed for traditional cardiovascular prognostic factors: patient demographics, cardiovascular risk factors, cardiac symptoms and clinical signs. Patients underwent extensive cardiac evaluation for underlying diagnosis: CMR ( $n=86,100 \%$ of patients), echocardiography $(\mathrm{n}=86,100 \%)$, coronary angiography $(\mathrm{n}=47,55 \%)$, stress and rest single-photon emission computed tomography (SPECT) $(\mathrm{n}=4,5 \%)$, one or more endomyocardial biopsies ( $n=41,48 \%$; total number of biopsy procedures 55), positron emission tomography (PET) $(\mathrm{n}=21,24 \%)$, electrophysiological study $(\mathrm{n}=14,16 \%)$, mediastinoscopy $(\mathrm{n}=4,5 \%)$ and explant histopathology after heart transplantation $(n=2,2 \%)$. The final diagnosis was reached using all available clinical information following the AHA 2006 guidelines of classification of cardiomyopathies [1]. 
Coronary angiography was done predominantly before CMR, based on the decision of treating cardiologist. Patients examined with neither angiography nor SPECT ( $\mathrm{n}=37,43 \%)$ were relatively young (median age $=45$ years), had only few CAD risk factors (the median number of risk factors was 1 out of 5 [dyslipidemia, hypertension, diabetes, smoking, family], interquartile range 0-1) and evident nonischemic etiology for symptoms. Patients were excluded due to ischemic cardiomyopathy if they had documented significant CAD, definition see above, presence of reversible perfusion defect in stress and rest SPECT or presence of CAD in explanted hearts.

Nonsustained VT was defined as six or more consecutive ventricular complexes lasting less than 30 seconds, and sustained VT with a duration of 30 seconds or more. Congestive heart failure (CHF) was defined using the 2008 guidelines of the European Society of Cardiology with the requirement of objective sign of fluid retention.

\section{CMR protocol and image analysis}

CMR imaging was performed with a 1.5- $\mathrm{T}$ imager (Avanto; Siemens, Erlangen, Germany) using 12-channel body-array coil as a receiver. Breath-hold cine CMR was performed using retrospectively electrocardiographically gated segmented true fast imaging with steady-state free-precession (SSFP). Cine CMR images were acquired in vertical, horizontal long-axis and short-axis planes covering the whole left ventricle. Typical imaging parameters were TR/TE 3.0/1.6 ms, flip angle 52 degrees, $256 \times 256$ matrix and $240 \times 340 \mathrm{~mm}$ field of view. Slice thickness was $6 \mathrm{~mm}$ and interslice gap 100\% (6 mm). The temporal resolution was $42-49 \mathrm{~ms}$. Five to fifteen minutes after intravenous injection of a contrast agent (gadoterate meglumine, Dotarem ${ }^{\odot} 0.1 \mathrm{mmol} / \mathrm{kg}$ ) LGE images were acquired in the same views as for cine images, using inversion-recovery turbo fast-low angle shot (FLASH). Typical imaging parameters were TR/TE 2.58/ $2.3 \mathrm{~ms}$, flip angle 50 degrees, $256 \times 256$ matrix, and $240 \times 340 \mathrm{~mm}$ field of view. Slice thickness was $8 \mathrm{~mm}$ and interslice gap $100 \%$ (8 mm). Inversion times were optimized to null the signal intensity of normal myocardium (240 - $360 \mathrm{~ms})$.

CMR images were analysed for the presence and extent of left ventricular LGE and SWMA by experienced cardiac radiologist blinded to clinical outcome. LGE was evaluated using the previously described visual scoring method based on the standard 17-segment model of the left ventricle [18]. In each segment, the percentage of enhancement was visually estimated and scored as 0 (no enhancement), 1 ( 0 - 25\% enhancement), 2 (26-50\% enhancement), 3 (51 - 75\% enhancement) or 4 (76-100\% enhancement). The global extent of LGE (LGE score) was calculated summing all segmental scores. To estimate the volume of LGE in the left ventricle, LGE score was then expressed as a percentage of the total maximum score $(4 \times 17=68)$ using formula: $100 \times($ LGE score $) / 68$.

Similarly, SWMA was visually estimated based on the 17-segment model using the scoring method validated for echocardiography and later used in CMR studies [21]. The degree of wall motion abnormality in each segment was scored as 0 (normokinesia), 1 (hypokinesia), 2 (akinesia) or 3 (dyskinesia). The global SWMA score of the left ventricle was then calculated as the sum of all segmental scores.

\section{Patient follow-up and endpoints of the study}

After CMR, patients were followed-up for major adverse cardiac events (MACE), including cardiovascular death, aborted sudden death or cardiac transplantation until April 30th 2012, based on information from medical records and mortality data from the national registry of Statistics Finland. For MACEs, event times were measured from the time of CMR to the first event. Aborted sudden death was defined as documented resuscitation from cardiac arrest or appropriate implantable cardioverterdefibrillator therapy, i.e. antitachycardia pacing or shock, for VT or ventricular fibrillation (VF). To meet the endpoint criteria, an event had to be distinct from baseline arrhythmias.

\section{Statistical analysis}

Continuous variables are presented as median (interquartile range $[\mathrm{IQR}]$ ) and categorical variables as frequency (\%), unless otherwise mentioned. Comparison between continuous variables was performed with Mann-Whitney $\mathrm{U}$ test and between categorical variables with Pearson Chi-Square test with continuity correction, Fisher's exact test or Mann-Whitney U test. A p-value of $<0.05$ was considered statistically significant and all statistical tests were 2-sided. Univariate Cox regression analysis was performed to study the prognostic significance of each predictive factor separately. Variables with statistical significance $\mathrm{p}<0.05$ (entry cut-off) were considered in the multivariate model. Forward stepwise multivariate Cox regression analysis was performed to study the independency of predictive variables, with a removal cut-off value of $\mathrm{p}=0.05$ for the final model. The number of variables in the model was limited to three in accordance with the limited number of events during follow-up (at least 5 events per each covariate). All variables in the multivariate model were tested to satisfy Cox proportional hazard assumption by plotting hazard function and logarithm of hazard function. If needed, continuous variables were made to dichotomous and cut-off values were taken from literature or close to median. Kaplan-Meier method was used to plot and compare (Log rank) survival curves. Receiver operating characteristic (ROC) curves were used to find the best cut-off values of LGE extent and SWMA 
extent (optimal combination of sensitivity and specificity) for the prediction of events. Statistical analysis was performed on SPSS 20 statistical package (SPSS, Chigaco, IL).

\section{Results}

\section{Patient characteristics}

Of the 86 patients with suspected NICM the median age was $53(42-61)$ years at the time of CMR and $39(45 \%)$ were female. Most common symptoms at presentation were decline in functional capacity (67\%), ventricular arrhythmias (40\%) and CHF (44\%). After extensive cardiac examinations, of all cohort patients suspected for NICM at baseline, 65 patients $(76 \%)$ were finally diagnosed with NICM, 15 (17\%) with left ventricle hypertrophy and 6 (7\%) with idiopathic arrhythmia, see Table 1. The most frequent disease entities were inflammatory cardiomyopathy $(\mathrm{n}=23,27 \%)$ and dilated cardiomyopathy (DCM) $(\mathrm{n}=22,26 \%)$. If a patient had several concomitant cardiac diseases, the disease considered to cause the current cardiac symptoms is presented.

Of all 86 patients, altogether 61 (71\%) had left ventricular LGE present on CMR. The median LGE extent in all patients was $7 \%(0-25 \%)$ of LV volume and in LGE positive patients alone 13\% (6 - 32\%). Altogether 56 patients (65\%) had SWMA, with a median SWMA score $4(0-12)$ in all patients and $7(4-19)$ in SWMA positive patients. In all 1462 segments (17 segments/patient $x 86$ patients) the extent of LGE and SWMA were significantly associated $(\mathrm{p}<0.001)$. Of all segments, 403 (28\%) had LGE and 472 (32\%) SWMA. Abnormal motion was found in $20 \%$ of segments without enhancement and in $75 \%$ of segments enhancing more than $50 \%$.

Table 1 Final diagnoses of all cohort patients suspected for nonischemic cardiomyopathy

\begin{tabular}{lc}
\hline & All patients $(\mathbf{n}=\mathbf{8 6})$ \\
\hline Nonischemic cardiomyopathy* & $65(76)$ \\
Inflammatory cardiomyopathy & $23(27)$ \\
Dilated cardiomyopathy & $22(26)$ \\
Cardiomyopathy nonspecific & $8(9)$ \\
Infiltrative cardiomyopathy or storage disease & $5(6)$ \\
Noncompaction cardiomyopathy & $3(3)$ \\
Hypertrophic cardiomyopathy & $2(2)$ \\
Tako-Tsubo cardiomyopathy & $1(1)$ \\
lon channelopathy (Long-QT syndrome) & $1(1)$ \\
Other diagnoses & $21(24)$ \\
Left ventricular hypertrophy** & $15(17)$ \\
Idiopathic arrhythmia & $6(7)$
\end{tabular}

Values are $\mathrm{n}(\%)$.

*Classification of (nonischemic) cardiomyopathies based on AHA 2006 guidelines [1]. Cardiomyopathy nonspecific had characters of several cardiomyopathies. **Hypertensive heart disease $(n=8)$ and left ventricular hypertrophy without hypertension $(n=7)$.
Baseline clinical characteristics and imaging parameters of all study patients and patients discriminated with the presence of LGE and SWMA are shown in Tables 2 and 3. At baseline, the presence of LGE (vs. absence of LGE) and SWMA (vs. absence of SWMA) were significantly associated with NYHA-class, CHF and LVEF. Both LGE positive (vs. LGE negative) and SWMA positive (vs. SWMA negative) patients had significantly higher NYHA-class (II vs. I, $\mathrm{p}=0.001$ for both), more frequent CHF (56\% vs. $16 \%, \mathrm{p}=0.002 ; 64 \%$ vs. $7 \%, \mathrm{p}<0.001$ ) and decreased median LVEF on CMR (45\% vs. $60 \%, \mathrm{p}<0.001$; $42 \%$ vs. $65 \%, \mathrm{p}<0.001)$. At baseline, there were no significant differences associated with the presence of LGE (vs. absence of LGE), or SWMA (vs. absence of SWMA), in myocardial injury biomarkers, arrhythmias or conducting abnormalities.

\section{Follow-up}

After CMR, patients were followed-up for MACE in median 835 (IQR: 780 - 998) days. Of 86 patients, altogether 15 (17\%, annual event rate: 7.6\%/year) reached an endpoint during follow-up: 5 cardiovascular deaths, 2 cardiac transplantations and 8 aborted sudden deaths.

Univariate Cox regression analysis was performed to find significant unadjusted predictors of MACE during follow-up, see Table 4. Significant predictors of adverse outcome were NYHA-class III-IV (hazard ratio [HR] 2.8, $\mathrm{p}=0.049)$, sustained VT (HR 3.8, $\mathrm{p}=0.023)$, atrioventricular block of any degree (HR 3.8, $\mathrm{p}=0.022)$, stroke volume (HR 0.968, $\mathrm{p}=0.032$ ), LVEF on CMR (HR 0.959 per $1 \%$ increase in LVEF, $\mathrm{p}=0.009)$, LGE volume (HR 1.028 per $1 \%$ increase in LGE, $\mathrm{p}<0.001$ ) and SWMA score (HR 1.067 per 1 point increase in SWMA, $\mathrm{p}=0.012$ ).

Considering the presence of LGE, there was an event rate of 26\% (14 of 61) in LGE positive patients compared with $4 \%$ ( 1 of 25$)$ in LGE negative patients $(\mathrm{p}=0.041$, Log rank), showing also a trend toward significance in Cox regression (HR 6.3, $\mathrm{p}=0.075$ ). Correspondingly, the presence of SWMA was a significant predictor of worse outcome during follow-up ( $\mathrm{p}=0.002$, Log rank), but the hazard ratio was not calculated since there were no events in the group of patients without SWMA.

Multivariate analysis was performed to find the adjusted predictors of MACE, see Table 5 . The best overall model to predict cardiac events included LGE volume (HR 1.027, $\mathrm{p}=0.003)$, sustained VT $(\mathrm{HR} 4.8, \mathrm{p}=0.011)$ and LVEF (HR 0.962, $\mathrm{p}=0.034$ ).

ROC curves of LGE volume, SWMA score and LVEF on CMR were analysed to find optimal cut-off values for prediction of events during follow-up, with corresponding area under curve (AUC) 0.832 (95\% confidence interval $[\mathrm{CI}]: 0.716-0.948), 0.769$ (95\% CI: $0.666-0.872$ ) and 0.704 (95\% CI: $0.565-0.844$ ), see Figure 1 . The cut-off value with the best combination 
Table 2 Baseline clinical characteristics of all patients, and patients discriminated with the presence of late gadolinium enhancement (LGE) and segmental wall motion abnormality (SWMA)

\begin{tabular}{|c|c|c|c|c|c|c|c|}
\hline & $\begin{array}{l}\text { All patients } \\
(n=86)\end{array}$ & $\begin{array}{c}\text { LGE negative } \\
(\mathrm{n}=25)\end{array}$ & $\begin{array}{c}\text { LGE positive } \\
(n=61)\end{array}$ & p-value & $\begin{array}{l}\text { SWMA negative } \\
(\mathrm{n}=\mathbf{3 0})\end{array}$ & $\begin{array}{c}\text { SWMA positive } \\
(n=56)\end{array}$ & $p$-value \\
\hline \multicolumn{8}{|l|}{ Demographics } \\
\hline Age, year & $53(42-61)$ & $49(42-59)$ & $53(42-63)$ & 0.278 & $51(42-59)$ & $53(42-62)$ & 0.336 \\
\hline Gender, female & $39(45)$ & $15(60)$ & $24(39)$ & 0.131 & $20(67)$ & $19(34)$ & 0.007 \\
\hline \multicolumn{8}{|l|}{ Cardiovascular risk factors } \\
\hline Dyslipidemia & $51(59)$ & $14(56)$ & $37(61)$ & 0.871 & $17(57)$ & $34(61)$ & 0.893 \\
\hline Hypertension & $34(40)$ & $7(28)$ & $27(44)$ & 0.247 & $10(33)$ & $24(43)$ & 0.529 \\
\hline Diabetes & $7(8)$ & $2(8)$ & $5(8)$ & 1.000 & $0(0)$ & $7(13)$ & 0.108 \\
\hline Smoking & $19(22)$ & $6(24)$ & $13(21)$ & 1.000 & $6(20)$ & $13(23)$ & 0.944 \\
\hline Family risk for $C A D$ & $11(13)$ & $5(20)$ & $6(10)$ & 0.285 & $5(17)$ & $6(11)$ & 0.504 \\
\hline Sum of risk factors & $1(1-2)$ & $1(0-2)$ & $1(1-2)$ & 0.513 & $1(1-2)$ & $1(1-2)$ & 0.406 \\
\hline \multicolumn{8}{|l|}{ Symptoms } \\
\hline Syncope or presyncope & $21(24)$ & $9(36)$ & $12(20)$ & 0.185 & $9(30)$ & $12(21)$ & 0.536 \\
\hline Palpitation & $34(40)$ & $13(52)$ & $21(34)$ & 0.204 & $14(47)$ & $20(36)$ & 0.448 \\
\hline Chest pain & $31(36)$ & $9(36)$ & $22(36)$ & 1.000 & $12(40)$ & $19(34)$ & 0.746 \\
\hline NYHA-class & $2(1-3)$ & $1(1-2)$ & $2(1-4)$ & 0.001 & $1(1-2)$ & $2(1-4)$ & 0.001 \\
\hline Congestive heart failure & $38(44)$ & $4(16)$ & $34(56)$ & 0.002 & $2(7)$ & $36(64)$ & $<0.001$ \\
\hline \multicolumn{8}{|l|}{ Arrhythmias } \\
\hline Atrial fibrillation & $25(29)$ & $6(24)$ & $19(31)$ & 0.688 & $5(17)$ & $20(36)$ & 0.109 \\
\hline Ventricular fibrillation & $9(10)$ & $3(12)$ & $6(10)$ & 0.715 & $3(10)$ & $6(11)$ & 1.000 \\
\hline Sustained VT & $9(10)$ & $1(4)$ & $8(13)$ & 0.274 & $1(3)$ & $8(14)$ & 0.152 \\
\hline Nonsustained VT & $16(19)$ & $6(24)$ & $10(16)$ & 0.542 & $5(17)$ & $11(20)$ & 0.962 \\
\hline \multicolumn{8}{|l|}{ Conducting abnormalities } \\
\hline AVB of any grade & $39(45)$ & $7(28)$ & $32(53)$ & 0.067 & $9(30)$ & $30(54)$ & 0.062 \\
\hline Distal AVB & $7(8)$ & $3(12)$ & $4(7)$ & 0.409 & $3(10)$ & $4(7)$ & 0.691 \\
\hline Cardiac enzyme elevation* & $32(37)$ & $8(32)$ & $24(39)$ & 0.693 & $9(30)$ & $23(41)$ & 0.436 \\
\hline
\end{tabular}

Values are median (IQR) or $\mathrm{n}(\%)$.

*Troponin T, Troponin I or CK-mb.

Abbreviations: AVB atrioventricular block, CAD coronary artery disease, IQR interquartile range, LGE late gadolinium enhancement, NYHA-class New York Heart Association classification of functional capacity, SWMA segmental wall motion abnormality, VT ventricular tachycardia.

of sensitivity and specificity for LGE volume was $\geq 17 \%$ (sensitivity: $80 \%$; specificity: $78 \%$ ), for SWMA extent score of $\geq 5$ (sensitivity: $80 \%$; specificity: $68 \%$ ) and for LVEF the percentage of $<46 \%$ (sensitivity $73 \%$; specificity: $65 \%$ ).

Kaplan Meier curves of event-free survival of patients discriminated with the presence of LGE (Log rank, $\mathrm{p}=0.041$ ) and with LGE volume $\geq 17 \%$ (Log rank, $\mathrm{p}<0.001$ ) demonstrate that there was a high risk group of 28 patients (LGE volume $\geq 17 \%$ ) with 12 events and a cumulative event ratio of $43 \%$ after three years (Figure $2 \mathrm{~A}$ and B). Patients with SWMA ( $\mathrm{p}=0.002$, Log rank) and patients with LVEF $<50 \%(\mathrm{p}=0.014, \log$ rank $)$ were also at increased risk (Figure 2C and D). Furthermore, in the patient cohort with preserved LVEF $(\geq 50 \%, 47$ patients), the absence of SWMA (30 patients) resulted in no events during follow-up, but 17 patients with SWMA were still at risk with 4 events (Log Rank, p=0.005) (Figure 2E).

\section{Discussion}

This study shows that in patients with suspected NICM, mainly presenting with ventricular arrhythmias or $\mathrm{CHF}$, the extent of LGE on CMR independently predicts MACE compared to traditional risk factors. Even though the final diagnosis is uncertain, extensive amount of LGE should be considered as a sign of poor prognosis and activate more intensive diagnostics and surveillance. Furthermore, the absence of SWMA on CMR was a strong predictor of good prognosis with no cardiac events during follow-up, giving additional prognostic information also in the subgroup of patients with preserved LVEF ( $\geq 50 \%)$. 
Table 3 Baseline imaging parameters of all patients, and patients discriminated with the presence of late gadolinium enhancement (LGE) and segmental wall motion abnormality (SWMA)

\begin{tabular}{|c|c|c|c|c|c|c|c|}
\hline & $\begin{array}{l}\text { All patients } \\
(\mathrm{n}=86)\end{array}$ & $\begin{array}{l}\text { LGE negative } \\
(\mathrm{n}=25)\end{array}$ & $\begin{array}{c}\text { LGE positive } \\
(\mathrm{n}=61)\end{array}$ & p-value & $\begin{array}{l}\text { SWMA negative } \\
(\mathrm{n}=30)\end{array}$ & $\begin{array}{l}\text { SWMA positive } \\
\quad(n=56)\end{array}$ & $\mathrm{p}$-value \\
\hline \multicolumn{8}{|l|}{ Echocardiography } \\
\hline LVEDD, mm & $55(48-61)$ & $48(44-54)$ & $56(50-63)$ & $<0.001$ & $48(44-54)$ & $59(53-67)$ & $<0.001$ \\
\hline LVEF, \% & $50(33-62)$ & $62(57-71)$ & $42(25-56)$ & $<0.001$ & $63(60-70)$ & $38(23-52)$ & $<0.001$ \\
\hline \multicolumn{8}{|l|}{ CMR } \\
\hline LVEDV, ml/m2 & $78(64-110)$ & $71(60-82)$ & $87(66-111)$ & 0.050 & $68(60-76)$ & $97(69-120)$ & $<0.001$ \\
\hline LVESV, $\mathrm{ml} / \mathrm{m} 2$ & $36(25-69)$ & $26(21-32)$ & $46(30-73)$ & 0.001 & $25(20-31)$ & $55(35-85)$ & $<0.001$ \\
\hline SV, ml & $73(58-85)$ & $75(65-89)$ & $72(55-84)$ & 0.227 & $76(65-82)$ & $70(52-88)$ & 0.291 \\
\hline LVEF, \% & $52(35-61)$ & $60(56-69)$ & $45(32-58)$ & $<0.001$ & $65(59-69)$ & $42(30-53)$ & $<0.001$ \\
\hline LGE presence & $61(71)$ & - & - & - & $9(30)$ & $52(93)$ & $<0.001$ \\
\hline LGE extent, score & $5(0-17)$ & - & $9(4-22)$ & - & $0(0-2)$ & $11(4-23)$ & $<0.001$ \\
\hline LGE extent, \% LV volume & $7(0-25)$ & - & $13(6-32)$ & - & $0(0-3)$ & $16(6-34)$ & $<0.001$ \\
\hline SWMA, presence & $56(65)$ & $4(16)$ & $52(85)$ & $<0.001$ & - & - & - \\
\hline SWMA extent, score & $4(0-12)$ & $0(0-0)$ & $5(3-17)$ & $<0.001$ & - & $7(4-19)$ & - \\
\hline
\end{tabular}

Values are median (IQR) or $\mathrm{n}(\%)$.

Abbreviations: CMR cardiovascular magnetic resonance, IQR interquartile range, $L V$ left ventricular, $L V E F$ left ventricular ejection fraction, $L G E$ late gadolinium enhancement, LVEDD left ventricle end-diastolic diameter, LVEDV left ventricle end-diastolic volume, LVESV left ventricle end-systolic volume, SV stroke volume, SWMA segmental wall motion abnormality.

\section{Prognostic value of LGE in NICM}

In our study, for every $1 \%$ increase in LGE volume, the risk of reaching MACE during follow-up increased 2.7\%, independently of sustained VT and LVEF. The highest event rate was observed in the patients with LGE volume of $\geq 17 \%$, with a cumulative event ratio of up to $43 \%$.

In earlier studies, the prognostic value of LGE has been documented in several disease entities of NICM. In DCM, the presence and extent of LGE, typically midwall replacement fibrosis, has been shown to provide independent and incremental prognostic information $[12,13,17]$. In hypertrophic cardiomyopathy (HCM), the presence and extent of LGE predict adverse outcome $[10,11]$ and lately in a systematic meta-analysis of 1,063 patients with HCM, during 3.1-year follow-up, the presence of LGE was associated with cardiac death and allcause mortality [26]. In suspected cardiac amyloidosis a characteristic circumferential endomyocardial LGE is a stronger predictor of mortality compared to other noninvasive parameters [15], and in suspected cardiac sarcoidosis the presence of LGE was the best adjusted predictor of adverse cardiac events [27]. Also, the presence of LGE has been shown to be the best independent predictor of mortality in biopsy-proven viral myocarditis compared to traditional cardiac signs and symptoms [28].

However, there is limited information on the prognostic value of LGE in nonselected consecutive patients with suspected or newly diagnosed NICM, reflecting the common clinical setting, and whether the quantification of LGE provides additional prognostic information in these patients. In a recent study of patients with newly diagnosed NICM, the presence of LGE was associated with worse prognosis, although only traditional risk markers, such as LV performance and cardiac biomarkers, were independent prognostic factors [8]. Our study adds to previous studies, that in clearly symptomatic patients with suspected NICM, the extent of LGE, along with its presence, carries prognostic value.

Of our study cohort, $76 \%$ of patients were eventually diagnosed with NICM, including $27 \%$ of patients with inflammatory cardiomyopathy. The histological basis for LGE in this sample was probably heterogenic, including replacement fibrosis, necrosis, oedema or amyloid infiltration. Patients with inflammatory cardiomyopathy may have wide-spread amounts of less intense LGE compared to myocardial infarction [29]. In this study, the optimal cut-off value for LGE extent for event prediction during follow-up was a volume of $\geq 17 \%$. This is higher compared to a recent cohort study of patients with nonischemic DCM with an indication for ICD, where the optimal cut-off value of LGE extent was $6.1 \%$ for event prediction [16]. This difference in cut-off values is probably explained by different patient cohorts; our study did not include just patients with DCM but patients with suspected NICM, of which $27 \%$ had finally inflammatory cardiomyopathy having higher LGE volume in LGE positive patients (mean 22\% [median 13\%]) compared to DCM patients (mean 9\%) in the other study. This demonstrates the importance of taking into account the reference patient 
Table 4 Univariate Cox regression analysis of event-free survival

\begin{tabular}{|c|c|c|c|}
\hline & HR & $95 \% \mathrm{Cl}$ & p-value \\
\hline \multicolumn{4}{|l|}{ Demographics } \\
\hline Age, year & 1.020 & $0.980-1.060$ & 0.333 \\
\hline Gender, female & 1.094 & $0.397-3.016$ & 0.863 \\
\hline \multicolumn{4}{|l|}{ Symptoms } \\
\hline Syncope or presyncope & 1.093 & $0.348-3.434$ & 0.879 \\
\hline Palpitation & 1.369 & $0.497-3.777$ & 0.544 \\
\hline Chest pain & 0.837 & $0.286-2.449$ & 0.745 \\
\hline NYHA-class (III - IV) & 2.820 & $1.003-7.928$ & 0.049 \\
\hline Congestive heart failure & 2.704 & $0.924-7.913$ & 0.069 \\
\hline \multicolumn{4}{|l|}{ Arrhythmias } \\
\hline Atrial fibrillation & 2.256 & $0.818-6.223$ & 0.116 \\
\hline Ventricular fibrillation & 0.559 & $0.073-4.250$ & 0.574 \\
\hline Sustained VT & 3.807 & $1.207-12.013$ & 0.023 \\
\hline Nonsustained VT & 1.122 & $0.317-3.975$ & 0.859 \\
\hline \multicolumn{4}{|l|}{ Conducting abnormalities } \\
\hline AVB of any grade & 3.801 & $1.210-11.945$ & 0.022 \\
\hline Distal AVB & 0.758 & $0.100-5.764$ & 0.789 \\
\hline Cardiac enzyme elevation* & 1.540 & $0.558-4.247$ & 0.404 \\
\hline \multicolumn{4}{|l|}{ CMR } \\
\hline LVEDV, $\mathrm{ml} / \mathrm{m} 2$ & 1.004 & $0.991-1.016$ & 0.556 \\
\hline LVESV, $\mathrm{ml} / \mathrm{m} 2$ & 1.008 & $0.996-1.020$ & 0.213 \\
\hline $\mathrm{SV}, \mathrm{ml}$ & 0.968 & $0.940-0.997$ & 0.032 \\
\hline LVEF, \% & 0.959 & $0.930-0.990$ & 0.009 \\
\hline LVEF $<50 \%$ & 3.813 & $1.213-11.981$ & 0.022 \\
\hline LGE, presence & 6.329 & $0.832-48.143$ & 0.075 \\
\hline LGE, extent, score & 1.042 & $1.019-1.065$ & $<0.001$ \\
\hline LGE, extent, \% LV volume & 1.028 & $1.013-1.044$ & $<0.001$ \\
\hline SWMA, presence* & & & 0.002 \\
\hline SWMA, extent, score & 1.067 & $1.014-1.122$ & 0.012 \\
\hline
\end{tabular}

*Troponin T, Troponin I or CK-mb.

**HR was not calculated for the presence of SWMA, since there were no events in the group of patients without SWMA; Univariate $p$-value was walculated with Log rank test.

Abbreviations: $A V B$ atrioventricular block, $C A D$ coronary artery disease, $C l$ confidence interval, CMR cardiovascular magnetic resonance, $H R$ hazard ratio, $L V$ left ventricular, $L V E F$ left ventricular ejection fraction, $L G E$ late gadolinium enhancement, $L V E D D$ left ventricle end-diastolic diameter, $L V E D V$ left ventricle end-diastolic volume, LVESV left ventricle end-systolic volume, NYHA-class New York Heart Association classification of functional capacity, SV stroke volume, SWMA segmental wall motion abnormality, VT ventricular tachycardia.

population, while choosing the optimal cut-off value for LGE in risk prediction. Also, importantly, after the etiology of NICM is diagnosed, LGE volume should be interpreted in the context of that disease.

The HR of 1.027 associated with LGE extent in predicting MACE was smaller compared to recent studies of DCM (HR = 1.11 or $\mathrm{HR}=1.16)[16,17]$, but similar to
Table 5 Multivariate Cox regression analysis of event-free survival

\begin{tabular}{lccc}
\hline & HR & $\mathbf{9 5 \% ~ C l}$ & p-value \\
\hline Model (forward stepwise) & & & \\
LGE extent, \% LV volume & 1.027 & $1.009-1.044$ & 0.003 \\
Sustained VT & 4.793 & $1.428-16.087$ & 0.011 \\
LVEF (CMR), \% & 0.962 & $0.929-0.997$ & 0.034 \\
\hline
\end{tabular}

Abbreviations: $\mathrm{Cl}$ confidence interval, $H R$ hazard ratio, LGE late gadolinium enhancement, $L V$ left ventricular, $L V E F$ left ventricular ejection fraction, $V T$ ventricular tachycardia.

a recent study of 217 consecutive HCM patients, in which LGE extent was associated with HR 1.15 for each 5\% increase in LGE volume [10]. The mean LGE extent (in LGE positive patients) was similar between our study patients and HCM study patients (22\% vs. $15.5 \%)$, but higher compared to DCM study patients (median $2.5 \%$ in the other, mean $9 \%$ in the other). Hence, in the sample of patients with relatively large amounts of LGE, a very small increase in LGE extent does not necessarily cause clinically meaningful increase in risk, although statistically significant.

\section{Prognostic value of segmental wall motion abnormality} In this study SWMA on CMR was present in $65 \%$ of patients. The unadjusted SWMA score predicted MACE

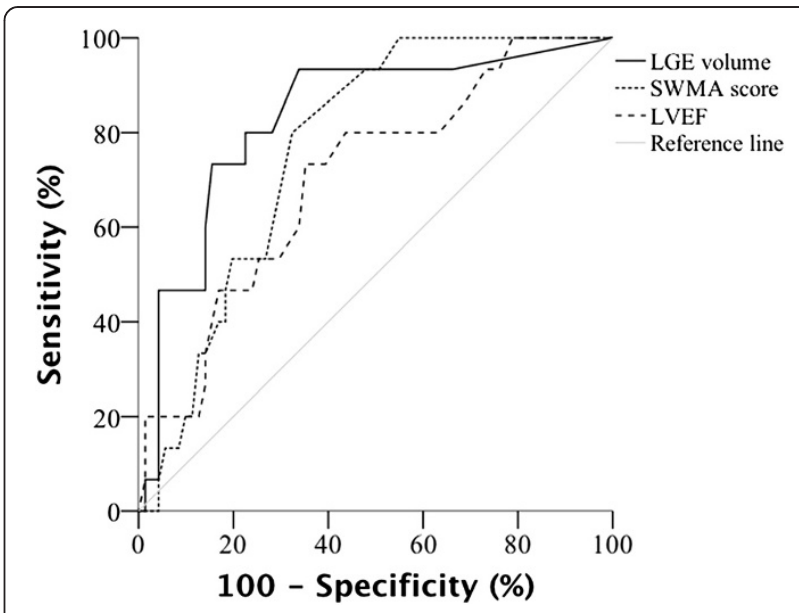

Figure 1 Receiver operating characteristic curves of late gadolinium enhancement (LGE) volume, segmental wall motion abnormality (SWMA) score and left ventricular ejection fraction (LVEF) for prediction of events during follow-up, with corresponding area under curve 0.832 (95\% confidence interval [Cl]: $0.716-0.948), 0.769$ (95\% Cl: $0.666-0.872)$ and 0.704 ( $95 \% \mathrm{Cl}: 0.565-0.844)$. In the patient cohort of suspected nonischemic cardiomyopathy with relatively high prevalence of LGE and SWMA (71\% and $65 \%$ of patients) at baseline, the optimal cut-off values with the best combination of sensitivity and specificity were LGE volume of $\geq 17 \%$, SWMA score of $\geq 5$ and LVEF $<46 \%$. 


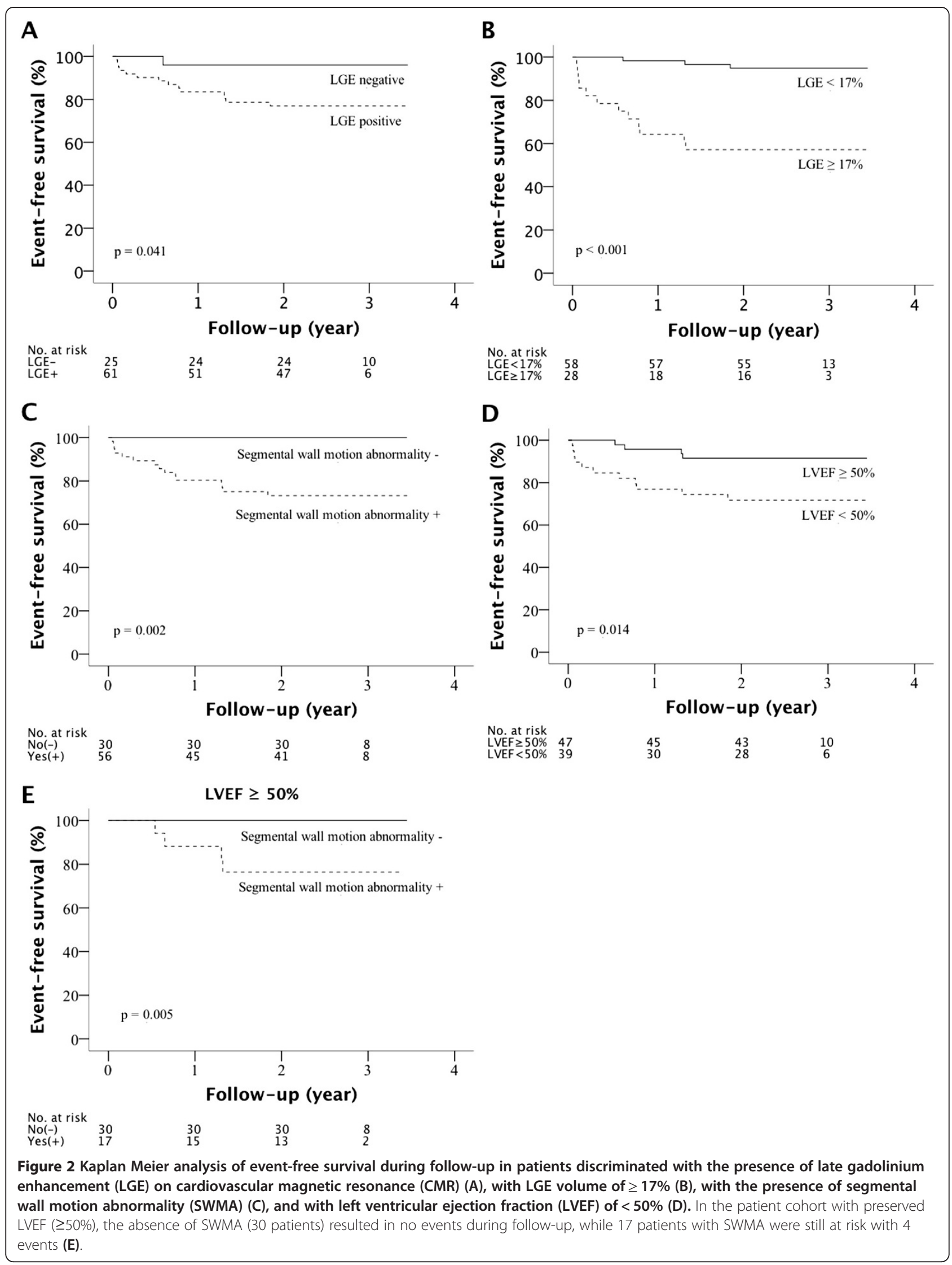


during follow-up (1 point increase in SWMA score was associated with $6.7 \%$ increase in risk), but not independently of traditional prognostic factors such as LVEF. It is natural that SWMA score and LVEF have strong interrelation, since they both are measures of global LV function [24]. However, the absence of SWMA was a strong predictor of good prognosis in our patients. Furthermore, SWMA may also give prognostic information beyond preserved LVEF $(\geq 50 \%)$, since in this subgroup patients with SWMA were still at risk for further events, although data was small.

\section{Study limitations}

This study employs an observational follow-up study design. The number of patients enrolled to the study and who eventually reached MACE during follow-up was limited. However, all endpoints were life-threatening events. The patient cohort with suspected NICM at presentation was heterogenic in final diagnoses. Thus, the results of this study should not be interpreted in specific cardiac disease entities. However, patients with suspected NICM reflect the real-life setting in which the need of CMR is considered. In this study we did not evaluate the additional prognostic value of LGE or SWMA in relation to final diagnoses, although it is known that the etiology of NICM has influence in outcome [3]. Also, it must be reminded that LGE visualizes only myocardial enhancement in relation to "normal" myocardium and has limited ability to detect diffuse myocardial changes. Recently introduced extracellular volume quantification method based on gadoliniumenhanced CMR and myocardial T1-mapping seems to be useful in detecting diffuse myocardial fibrosis or homogeneously distributed infiltration, seen in many forms of NICM, thus potentially providing further prognostic information [30]. Finally, the presented cut-off values for LGE extent in this study represent only our patient sample, demonstrating the effect of increasing LGE on patient outcomes, and should be tested in independent study population.

\section{Conclusions}

In suspected NICM, presenting with ventricular arrhythmias or heart failure, LGE extent gives additional prognostic information compared to traditional risk factors, while the absence of segmental wall motion abnormality may give prognostic information beyond normal LVEF. Even though the final diagnosis is uncertain in NICM, extensive amount of LGE should be considered as a sign of poor prognosis and activate more intensive diagnostics and surveillance.

\section{Competing interests}

The authors declare that they have no competing interests.

\section{Authors' contributions}

PP participated in study design, acquisition of data, analysis and interpretation of data, statistical analysis and writing the manuscript. SK participated in study design, CMR image analysis and interpretation, and writing the manuscript. $\mathrm{MH}$ participated in study design, CMR image analysis and interpretation, and writing the manuscript. $\mathrm{HH}$ participated in study design and coordination, interpretation of data, and writing the manuscript. All authors read and approved the manuscript.

\section{Acknowledgements}

We would like to thank the national registry of Statistics Finland for mortality information; Jari Haukka for statistical advice and Mika Laine for ideas considering the study design.

\section{Funding}

Conducting this study, PP was supported by Aarne Koskelo Foundation for medical research and Finnish government grant for medical research (EVO)

\section{Author details}

${ }^{1}$ Heart and Lung Center, Division of Cardiology, Helsinki University Central Hospital, Po BOX 340, 00029 HUCH Helsinki, Finland. ${ }^{2}$ Medical Imaging Center, Helsinki University Central Hospital, Helsinki, Finland.

\section{Received: 28 March 2014 Accepted: 19 August 2014}

Published: 27 August 2014

\section{References}

1. Maron BJ, Towbin JA, Thiene G, Antzelevitch C, Corrado D, Arnett D, Moss AJ Seidman CE, Young JB, American Heart Association, Council on Clinical Cardiology, Heart Failure and Transplantation Committee, Quality of Care and Outcomes Research and Functional Genomics and Translational Biology Interdisciplinary Working Groups, Council on Epidemiology and Prevention: Contemporary definitions and classification of the cardiomyopathies: an American Heart Association Scientific Statement from the Council on Clinical Cardiology, Heart Failure and Transplantation Committee; Quality of Care and Outcomes Research and Functional Genomics and Translational Biology Interdisciplinary Working Groups; and Council on Epidemiology and Prevention. Circulation 2006, 113(14):1807-1816.

2. Huikuri HV, Castellanos A, Myerburg RJ: Sudden death due to cardiac arrhythmias. N Engl J Med 2001, 345(20):1473-1482.

3. Felker GM, Thompson RE, Hare JM, Hruban RH, Clemetson DE, Howard DL, Baughman KL, Kasper EK: Underlying causes and long-term survival in patients with initially unexplained cardiomyopathy. N Engl J Med 2000, 342(15):1077-1084.

4. Cooper LT, Baughman KL, Feldman AM, Frustaci A, Jessup M, Kuhl U, Levine GN, Narula J, Starling RC, Towbin J, Virmani R, American Heart Association, American College of Cardiology, European Society of Cardiology, Heart Failure Society of America, Heart Failure Association of the European Society of Cardiology: The role of endomyocardial biopsy in the management of cardiovascular disease: a scientific statement from the American Heart Association, the American College of Cardiology, and the European Society of Cardiology. Endorsed by the Heart Failure Society of America and the Heart Failure Association of the European Society of Cardiology. J Am Coll Cardiol 2007, 50(19):1914-1931.

5. Gradman AF, Deedwania PF, Cody RF, Massie BF, Packer MF, Pitt BF, Goldstein S: Predictors of total mortality and sudden death in mild to moderate heart failure. Captopril-Digoxin Study Group. J Am Coll Cardiol 1989, 14(3):564-572

6. Wu KC, Weiss RG, Thiemann DR, Kitagawa K, Schmidt A, Dalal D, Lai S, Bluemke DA, Gerstenblith G, Marban E, Tomaselli GF, Lima JA: Late gadolinium enhancement by cardiovascular magnetic resonance heralds an adverse prognosis in nonischemic cardiomyopathy. J Am Coll Cardiol 2008, 51(25):2414-2421.

7. Cheong BY, Muthupillai R, Wilson JM, Sung A, Huber S, Amin S, Elayda MA, Lee W, Flamm SD: Prognostic significance of delayed-enhancement magnetic resonance imaging: survival of 857 patients with and without left ventricular dysfunction. Circulation 2009, 120(21):2069-2076.

8. Muller KA, Muller I, Kramer U, Kandolf R, Gawaz M, Bauer A, Zuern CS: Prognostic value of contrast-enhanced cardiac magnetic resonance imaging in patients with newly diagnosed non-ischemic cardiomyopathy: cohort study. PLoS One 2013, 8(2):e57077. 
9. Kuruvilla S, Adenaw N, Katwal AB, Lipinski MJ, Kramer CM, Salerno M: Late gadolinium enhancement on cardiac magnetic resonance predicts adverse cardiovascular outcomes in nonischemic cardiomyopathy: a systematic review and meta-analysis. Circ Cardiovasc Imaging 2014, 7(2):250-258.

10. O'Hanlon R, Grasso A, Roughton M, Moon JC, Clark S, Wage R, Webb J, Kulkarni M, Dawson D, Sulaibeekh L, Chandrasekaran B, Bucciarelli-Ducci C, Pasquale F, Cowie MR, McKenna WJ, Sheppard MN, Elliott PM, Pennell DJ, Prasad SK: Prognostic significance of myocardial fibrosis in hypertrophic cardiomyopathy. J Am Coll Cardiol 2010, 56(11):867-874.

11. Bruder O, Wagner A, Jensen CJ, Schneider S, Ong P, Kispert EM, Nassenstein K, Schlosser T, Sabin GV, Sechtem U, Mahrholdt H: Myocardial scar visualized by cardiovascular magnetic resonance imaging predicts major adverse events in patients with hypertrophic cardiomyopathy. J Am Coll Cardiol 2010, 56(11):875-887.

12. Assomull RG, Prasad SK, Lyne J, Smith G, Burman ED, Khan M, Sheppard MN, Poole-Wilson PA, Pennell DJ: Cardiovascular magnetic resonance, fibrosis, and prognosis in dilated cardiomyopathy. J Am Coll Cardiol 2006, 48(10):1977-1985.

13. Lehrke S, Lossnitzer D, Schob M, Steen H, Merten C, Kemmling H, Pribe R, Ehlermann P, Zugck C, Korosoglou G, Giannitsis E, Katus HA: Use of cardiovascular magnetic resonance for risk stratification in chronic heart failure: prognostic value of late gadolinium enhancement in patients with non-ischaemic dilated cardiomyopathy. Heart 2011, 97(9):727-732.

14. Wu E, Ortiz JT, Tejedor P, Lee DC, Bucciarelli-Ducci C, Kansal P, Carr JC, Holly TA, Lloyd-Jones D, Klocke FJ, Bonow RO: Infarct size by contrast enhanced cardiac magnetic resonance is a stronger predictor of outcomes than left ventricular ejection fraction or end-systolic volume index: prospective cohort study. Heart 2008, 94(6):730-736.

15. Austin BA, Tang WH, Rodriguez ER, Tan C, Flamm SD, Taylor DO, Starling RC, Desai MY: Delayed hyper-enhancement magnetic resonance imaging provides incremental diagnostic and prognostic utility in suspected cardiac amyloidosis. JACC Cardiovasc Imaging 2009, 2(12):1369-1377.

16. Neilan TG, Coelho-Filho OR, Danik SB, Shah RV, Dodson JA, Verdini DJ, Tokuda M, Daly CA, Tedrow UB, Stevenson WG, Jerosch-Herold M, Ghoshhajra BB, Kwong RY: CMR Quantification of Myocardial Scar Provides Additive Prognostic Information in Nonischemic Cardiomyopathy. JACC Cardiovasc Imaging 2013, 6(9):944-954.

17. Gulati A, Jabbour A, Ismail TF, Guha K, Khwaja J, Raza S, Morarji K, Brown TD, Ismail NA, Dweck MR, Di Pietro E, Roughton M, Wage R, Daryani Y, O'Hanlon R, Sheppard MN, Alpendurada F, Lyon AR, Cook SA, Cowie MR, Assomull RG, Pennell DJ, Prasad SK: Association of fibrosis with mortality and sudden cardiac death in patients with nonischemic dilated cardiomyopathy. JAMA 2013, 309(9):896-908.

18. Comte A, Lalande A, Walker PM, Cochet A, Legrand L, Cottin Y, Wolf JE, Brunotte F: Visual estimation of the global myocardial extent of hyperenhancement on delayed contrast-enhanced MRI. Eur Radiol 2004, 14(12):2182-2187

19. Mewton N, Revel D, Bonnefoy E, Ovize M, Croisille P: Comparison of visual scoring and quantitative planimetry methods for estimation of global infarct size on delayed enhanced cardiac MRI and validation with myocardial enzymes. Eur J Radiol 2011, 78(1):87-92.

20. Doesch C, Huck S, Bohm CK, Michaely H, Fluechter S, Haghi D, Dinter D, Borggrefe M, Papavassiliu T: Visual estimation of the extent of myocardial hyperenhancement on late gadolinium-enhanced CMR in patients with hypertrophic cardiomyopathy. Magn Reson Imaging 2010, 28(6):812-819.

21. Lang RM, Bierig M, Devereux RB, Flachskampf FA, Foster E, Pellikka PA, Picard MH, Roman MJ, Seward J, Shanewise JS, Solomon SD, Spencer KT, Sutton MS, Stewart WJ, Chamber Quantification Writing Group, American Society of Echocardiography's Guidelines and Standards Committee, European Association of Echocardiography: Recommendations for chamber quantification: a report from the American Society of Echocardiography's Guidelines and Standards Committee and the Chamber Quantification Writing Group, developed in conjunction with the European Association of Echocardiography, a branch of the European Society of Cardiology. J Am Soc Echocardiogr 2005, 18(12):1440-1463.

22. Pujadas S, Reddy GP, Weber O, Lee JJ, Higgins CB: MR imaging assessment of cardiac function. J Magn Reson Imaging 2004, 19(6):789-799.
23. Mahrholdt H, Wagner A, Holly TA, Elliott MD, Bonow RO, Kim RJ, Judd RM: Reproducibility of chronic infarct size measurement by contrast-enhanced magnetic resonance imaging. Circulation 2002, 106(18):2322-2327.

24. Scholl D, Kim HW, Shah D, Fine NM, Tandon S, Thompson T, Drangova M, White JA: Validation of a novel modified wall motion score for estimation of left ventricular ejection fraction in ischemic and non-ischemic cardiomyopathy. Eur J Radiol 2012, 81(8):e923-e928.

25. Felker GM, Shaw LK, O'Connor CM: A standardized definition of ischemic cardiomyopathy for use in clinical research. J Am Coll Cardiol 2002, 39(2):210-218

26. Green JJ, Berger JS, Kramer CM, Salerno M: Prognostic value of late gadolinium enhancement in clinical outcomes for hypertrophic cardiomyopathy. JACC Cardiovasc Imaging 2012, 5(4):370-377.

27. Greulich S, Deluigi CC, Gloekler S, Wahl A, Zurn C, Kramer U, Nothnagel D, Bultel H, Schumm J, Grun S, Ong P, Wagner A, Schneider S, Nassenstein K, Gawaz M, Sechtem U, Bruder O, Mahrholdt H: CMR imaging predicts death and other adverse events in suspected cardiac sarcoidosis. JACC Cardiovasc Imaging 2013, 6(4):501-511.

28. Grun S, Schumm J, Greulich S, Wagner A, Schneider S, Bruder O, Kispert EM, Hill S, Ong P, Klingel K, Kandolf R, Sechtem U, Mahrholdt H: Long-term follow-up of biopsy-proven viral myocarditis: predictors of mortality and incomplete recovery. J Am Coll Cardiol 2012, 59(18):1604-1615.

29. Friedrich MG, Sechtem U, Schulz-Menger J, Holmvang G, Alakija P, Cooper LT, White JA, Abdel-Aty H, Gutberlet M, Prasad S, Aletras A, Laissy JP, Paterson I, Filipchuk NG, Kumar A, Pauschinger M, Liu P, International Consensus Group on Cardiovascular Magnetic Resonance in Myocarditis: Cardiovascular magnetic resonance in myocarditis: A JACC White Paper. J Am Coll Cardiol 2009, 53(17):1475-1487.

30. Moon JC, Messroghli DR, Kellman P, Piechnik SK, Robson MD, Ugander M, Gatehouse PD, Arai AE, Friedrich MG, Neubauer S, Schulz-Menger J, Schelbert EB: Myocardial T1 mapping and extracellular volume quantification: a Society for Cardiovascular Magnetic Resonance (SCMR) and CMR Working Group of the European Society of Cardiology consensus statement. J Cardiovasc Magn Reson 2013, 15:92-429X-15-92.

doi:10.1186/1471-2261-14-110

Cite this article as: Pöyhönen et al:: Quantifying late gadolinium enhancement on CMR provides additional prognostic information in early risk-stratification of nonischemic cardiomyopathy: a cohort study. BMC Cardiovascular Disorders 2014 14:110.

\section{Submit your next manuscript to BioMed Central and take full advantage of:}

- Convenient online submission

- Thorough peer review

- No space constraints or color figure charges

- Immediate publication on acceptance

- Inclusion in PubMed, CAS, Scopus and Google Scholar

- Research which is freely available for redistribution 